\title{
Low-frequency sounds induce acoustic trauma in cephalopods
}

\author{
Michel André ${ }^{*}$, Marta Solé ${ }^{1}$, Marc Lenoir ${ }^{2}$, Mercè Durfort ${ }^{3}$, Carme Quero ${ }^{4}$, Alex Mas ${ }^{1}$, Antoni Lombarte ${ }^{5}$, \\ Mike van der Schaar ${ }^{1}$, Manel López-Bejar ${ }^{6}$, Maria Morell ${ }^{1}$, Serge Zaugg ${ }^{1}$, and Ludwig Houégnigan ${ }^{1}$
}

\begin{abstract}
There is currently relatively little information on how marine organisms process and analyze sound, making assessments about the impacts of artificial sound sources in the marine environment difficult. However, such assessments have become a priority because noise is now considered as a source of pollution that increasingly affects the natural balance of marine ecosystems. We present the first morphological and ultrastructural evidence of massive acoustic trauma, not compatible with life, in four cephalopod species subjected to low-frequency controlled-exposure experiments. Exposure to low-frequency sounds resulted in permanent and substantial alterations of the sensory hair cells of the statocysts, the structures responsible for the animals' sense of balance and position. These results indicate a need for further environmental regulation of human activities that introduce high-intensity, low-frequency sounds in the world's oceans.
\end{abstract}

Front Ecol Environ 2011; 9(9): 489-493, doi:10.1890/100124 (published online 11 Apr 2011)

$\mathrm{T}$ he underwater marine environment is filled with natural sounds, but anthropogenic sound sources are increasingly contributing to the general noise budget of the oceans. The extent to which excessive noise in the sea impacts marine life is a topic of considerable concern to the scientific community, environmental groups, and the general public. Sounds produced by human activities can cause physical, physiological, and behavioral effects in marine fauna (including mammals, reptiles, fish, and invertebrates); these effects can be diverse, depending on the spatial proximity of the organism to the sound source. These impacts can result in a reduction in the abundance of fish species, changes in cetacean behavior and migration routes, and a range of physical injuries in both marine vertebrates and invertebrates (Richardson et al. 1995). There may be further long-term consequences due to chronic exposure, and sound can also indirectly affect animals through changes in the accessibility of prey, which may also suffer the adverse effects of acoustic pollution (Richardson et al. 1995). These effects could negatively affect the conservation of already endangered species that use acoustically contaminated areas for migration, reproduction, and feeding.

Evaluating the acoustic impacts of artificial sound

${ }^{1}$ Laboratory of Applied Bioacoustics, Technical University of Catalonia, Barcelona, Spain * (michel.andre@upc.edu); ${ }^{2}$ INSERM U.1051, Institute of Neurosciences of Montpellier, Montpellier, France; ${ }^{3}$ Department of Cellular Biology, Faculty of Biology, University of Barcelona, Barcelona, Spain; ${ }^{4}$ Department of Biological Chemistry and Molecular Modelling, IQAC-CSIC, Barcelona, Spain; ${ }^{5}$ Renewable Marine Resources Department, Marine Sciences Institute (ICM CMIMA-CSIC), Barcelona, Spain; ${ }^{6}$ Department of Animal Health and Anatomy, Faculty of Veterinary Science, Autonomous University of Barcelona, Cerdanyola del Vallès, Spain

Beyond the Frontier: Listen to Michel André discussing this research on Frontiers' monthly podcast, at www.frontiersinecology.org. sources in the marine environment is a complex and expensive undertaking. First, there has been relatively little research on the sound-processing and analysis mechanisms in marine organisms. Although it is possible to cata$\log$ and record the majority of these sound signals, we still do not know enough about the role sounds play in the balance and development of populations. Second, these sound emissions may not only affect auditory reception systems, but might also interfere with other sensory and systemic organs and processes, with possibly lethal consequences for the affected animal. Furthermore, prolonged or regular exposure to a specific sound may have negative short-, medium-, or long-term consequences. The lack of past research has contributed to the difficulty in obtaining objective data to inform future decisions on the effective control of anthropogenic noise in the oceans.

Another pressing problem relates to the homogenization of measurements. At the moment, there is no welldefined protocol for measuring marine acoustic pollution or any agreement on the best way of depicting the results of these measurements. Although levels of noise pollution in the marine environment are increasing, the variability of the available parameters to measure the resulting effects leads to heterogeneous or fragmented data that appear to be of little use in developing effective management programs (André et al. 2010).

Finally, most studies lack information on the long-term effects of sound sources on specific populations and individual species. There are very few datasets showing current ambient noise levels in most areas of the marine ecosystem, and even less historical data. Information on trends is not available, either for European or international waters. According to the US Marine Mammal Commission, underwater ambient sound levels will increase over time, as a result of human activities (eg shipping, offshore industrial construction, resource 


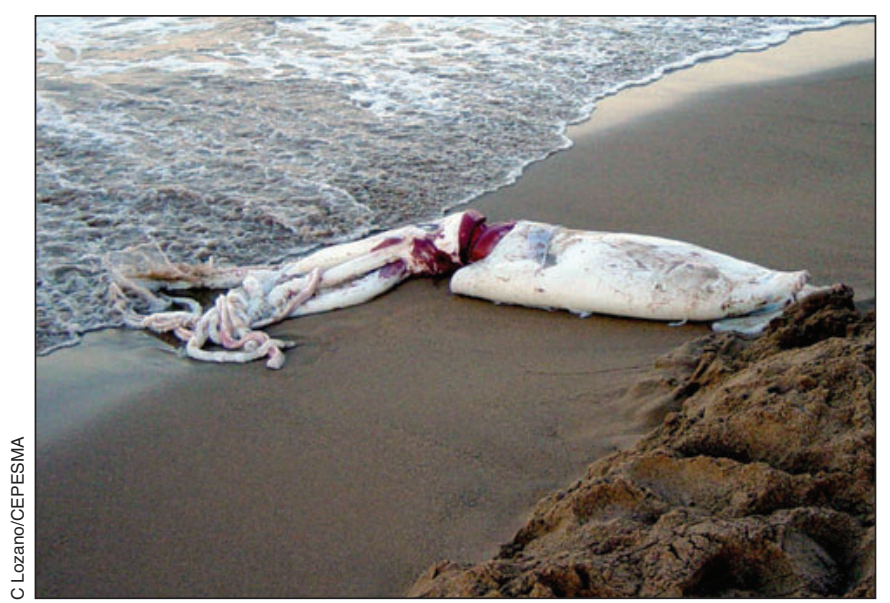

Figure 1. A giant squid (Architeuthis dux) carcass on a beach in Spain.

exploitation) in the marine environment (Marine Mammal Commission 2007). In addition, the potential increase in ambient sound levels will not affect all areas equally, but will differentially impact specific regions where offshore activity is high (eg some of the Exclusive Economic Zones; see OSPAR Commission 2009). Potential effects might not be proportionate to noise pollution levels due to variation in sound propagation and, most importantly, the distribution of marine organisms that are sensitive to sound.

Recently, the UN's Convention on Migratory Species (CMS) recognized that "anthropogenic ocean noise constitutes a form of pollution [that] may degrade the marine environment and also have adverse effects on ocean fauna, even resulting in individual fatalities, and reaffirming that the difficulty in determining the negative acoustic impact on organisms requires the drawing up of precautionary principles in cases where impact is possible" (COP 2008). The CMS urged agencies that exercise jurisdiction over any species of marine organisms listed in the appendices of the Conference of the Parties (COP 2008) to "develop methods of control on the impact of acoustic emissions arising from human activities in susceptible habitats that serve as gathering points or places of passage of endangered species, and to carry out environmental impact studies on the introduction of systems that may produce noise and their derived risks to marine species" (COP 2008).

The European Union's Marine Strategy Framework Directive (2008/56/EC), which aims to improve the condition of all Europe's seas and ensure that human usage of these seas is sustainable, includes a series of objectives for eleven Descriptors of Environmental Status. One of these Descriptors concerns underwater noise: "Introduction of energy, including underwater noise, is at levels that do not adversely affect the marine environment". Descriptor 11 (Tasker et al. 2010) specifically addresses noise sources from pile-driving operations and seismic surveys (low- and mid-frequency implusive sounds) and from shipping (lowfrequency continuous sounds).
Interestingly, most studies of noise effects on marine organisms concern endangered species that use sound in their daily activities. Less attention has been paid to commercially valuable species and in particular to invertebrates, such as cephalopods.

In a comprehensive review of the effects of anthropogenic sound sources on fish, Popper and Hastings (2009) concluded that without data "obtained in a systematic way with excellent controls and peer review" it is impossible to develop clear sound-exposure metrics and criteria that could help predict and manage the potential effects of sound on marine life. Indeed, reliable data in this field are extremely limited and, in light of the scope and importance of ocean systems, are urgently required. Of the three main forms of marine macrofauna (mammals, fish, and invertebrates), cephalopods belong to the last group, about which the least is understood. Situated in the food chain between fish and marine mammals, they are also key bio-indicators for ecosystem balance in the vast and complex marine ecosystem.

In September and October 2001, and again in October 2003, the annual reports of strandings of giant squid (Architeuthis dux; Figure 1) along the west coast of Asturias, Spain, showed a statistically significant increase (Guerra et al. 2004a). In both instances, the deaths coincided with the proximity of vessels using compressed airguns for geophysical prospecting, and producing high-intensity, low-frequency (below 100 hertz $[\mathrm{Hz}]$ ) sound waves. Some of the specimens had lesions in various tissues and organs, but all presented pathologies within the statocysts. Because none of these lesions could be linked to previously known causes of death in the species, the presence of geophysical prospecting vessels in the area suggested for the first time that the deaths could be related to excessive sound exposure (Guerra et al. 2004b). However, although startle responses were observed in caged cephalopods exposed to airguns (McCauley et al. 2000), no studies addressing noise-induced morphological changes in these species were carried out, and doubts remained regarding the possible negative impacts of highintensity, low-frequency sounds on cephalopods.

Little is known about sound perception in invertebrates, but some evidence suggests that cephalopods may be sensitive to low-frequency sounds (Hanlon and Budelmann 1987; Packard et al. 1990). All cephalopod species have statocysts in the cephalic cartilage region. These highly sophisticated structures are responsible for helping the animal to determine its position and maintain balance, and are analogous to the vestibular system of vertebrates (Offutt 1970; Budelmann 1988; Budelmann 1992; Williamson 1995). These balloon-shaped structures contain sensory hair cells, which line the inside wall of a saclike structure (Budelmann 1988) and include two receptor systems: the macula-statolith system, which indicates changes in position according to gravity and linear acceleration, and the crista-cupula system, which determines angular acceleration (Figure 2).

Statocysts may play an important additional role in 
low-frequency sound reception (Hu et al. 2009), although to date there is no definitive scientific evidence to support this idea. While there is uncertainty regarding the biological importance of particle motion sensitivity versus acoustic pressure, recent electrophysiological studies confirmed the cephalopods' sensitivity to frequencies under $400 \mathrm{~Hz}$ (Octopus vulgaris, Kaifu et al. 2008; Sepioteuthis lessoniana, Octopus vulgaris, Hu et al. 2009; Loligo pealei, Mooney et al. 2010).

Here, we present the first morphological and ultrastructural study of the damaging effects on statocysts in individuals belonging to four cephalopod species under lowfrequency, controlled-exposure experiments (CEEs), and discuss the implications of our findings.

\section{Methods}

Sequential CEEs were conducted over a period of 2 years on adult individuals $(n=87)$ belonging to four cephalopod species (Loligo vulgaris [ $n=5]$, Sepia officinalis [ $n=76$ ], Octopus vulgaris $[n=4]$, and Illex coindetii $[n=2])$ that were freshly caught off the Catalan coast of Spain (northwest Mediterranean Sea). The protocol included immediate exposure to $50-400 \mathrm{~Hz}$ sinusoidal wave sweeps with $100 \%$ duty cycle and 1 -second sweep period for 2 hours in either a 2.000-liter fiberglass reinforced plastic tank or a 200-liter (glass-walled) tank, both filled with natural seawater (physiochemically self-filtered; temperature $18-20^{\circ} \mathrm{C}$; salinity 35 parts per thousand; and under natural oxygen pressure). The sweep was produced and amplified through an in-air loudspeaker, while the level received was measured by a calibrated B\&K 8106 hydrophone (received sound pressure level: $157 \pm 5$ decibels $[\mathrm{dB}]$ in reference to [re] 1 microPascal $[\mu \mathrm{Pa}$ ], with peak levels at $175 \mathrm{~dB}$ re $1 \mu \mathrm{Pa}$ ).

Following exposure, the non-anesthetized individuals were decapitated at different intervals, ranging from immediately afterward to $12,24,48,72$, and 96 hours after exposure, respectively. The extraction of the statocysts was performed immediately following decapitation and the tissue was fixed for scanning electron microscopy (SEM), for light microscopy (LM), and for transmission electron microscopy (TEM). Specimens were then processed according to classical SEM, LM, and TEM procedures. In addition, the endolymph was extracted from a further set of individuals and immediately frozen at $-70^{\circ} \mathrm{C}$ for proteomic analysis.

An additional set of live adult individuals $(n=100)$ was used as a control and sequentially processed in the same manner as the noise-exposed cephalopods, immediately following capture.

\section{Results}

All exposed individuals from all four species presented the same lesions and the same incremental effects over time. Immediately after exposure, damage was observed in the macula statica princeps (msp) and on the crista sensory

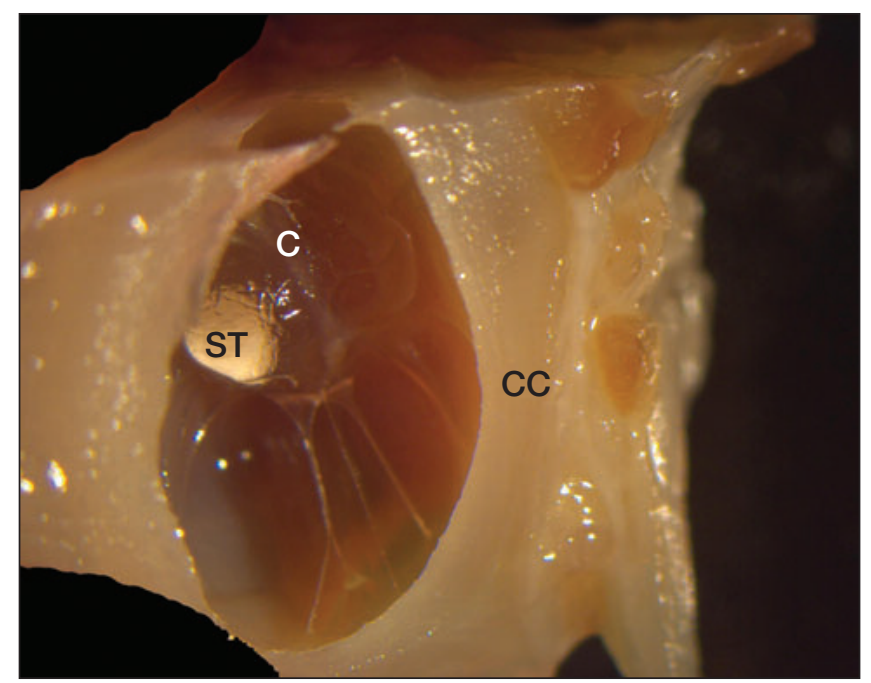

Figure 2. Lateral view of the interior of a statocyst in Octopus vulgaris. Photomicrograph shows the spherical inner sac suspended in the cephalic cartilage (CC) cavity by fibrous strands. The statolith (ST) is attached to the macula. Both the macula and the crista (C) lie on the inside wall of the sac-like structure.

epithelia. Kinocilia within hair cells were either missing or were bent or flaccid (compare Figure 3a and 3b). A number of hair cells showed protruding apical poles (Figure 3b) and ruptured plasma membranes, most probably resulting from the extrusion of cytoplasmic material. Hair cells were also partially ejected from the sensory epithelium, and spherical holes corresponding to missing hair cells were visible in the epithelium. The cytoplasmic content of the damaged hair cells showed obvious changes, including the presence of numerous vacuoles and electron dense inclusions not seen in the control animals (compare Figure $3 \mathrm{c}$ and $3 \mathrm{~d}$ ). Underneath the hair cells, afferent nerve fibers were swollen and showed mitochondrial damage or complete degeneration. In some specimens, large holes in the sensory epithelium were also observed. The appearance of these lesions became gradually more pronounced in individuals after 12 , 24, 48, 72, and 96 hours. Part of the cellular body of the damaged cells was extruded above the sensory epithelium into the statocyst cavity (inset in Figure 3b). The most pronounced lesions were visible in specimens observed 96 hours after sound exposure. In these individuals, the sensory epithelium was severely damaged, with very few hair cells remaining; most of the hair cells had been extruded. The epithelium only presented supporting cells, creating a holed mosaic, where residual hair cells showed either very few bent, flaccid, or fused kinocilia, or none at all.

The almost complete extrusion of the hair cells, as well as the holes present in the epithelium, are clear signs that the noise impact was acute and that hair-cell damage was immediate. In mammals and some fish species, such dramatic damage has only been observed after exposure to extremely high-intensity sound; low- to mid-intensity acoustic stimuli have to date not been known to lead to any obvious mechanical damage to the sensory epithelia (Pujol and Puel 1999; McCauley et al. 2003; Popper and 

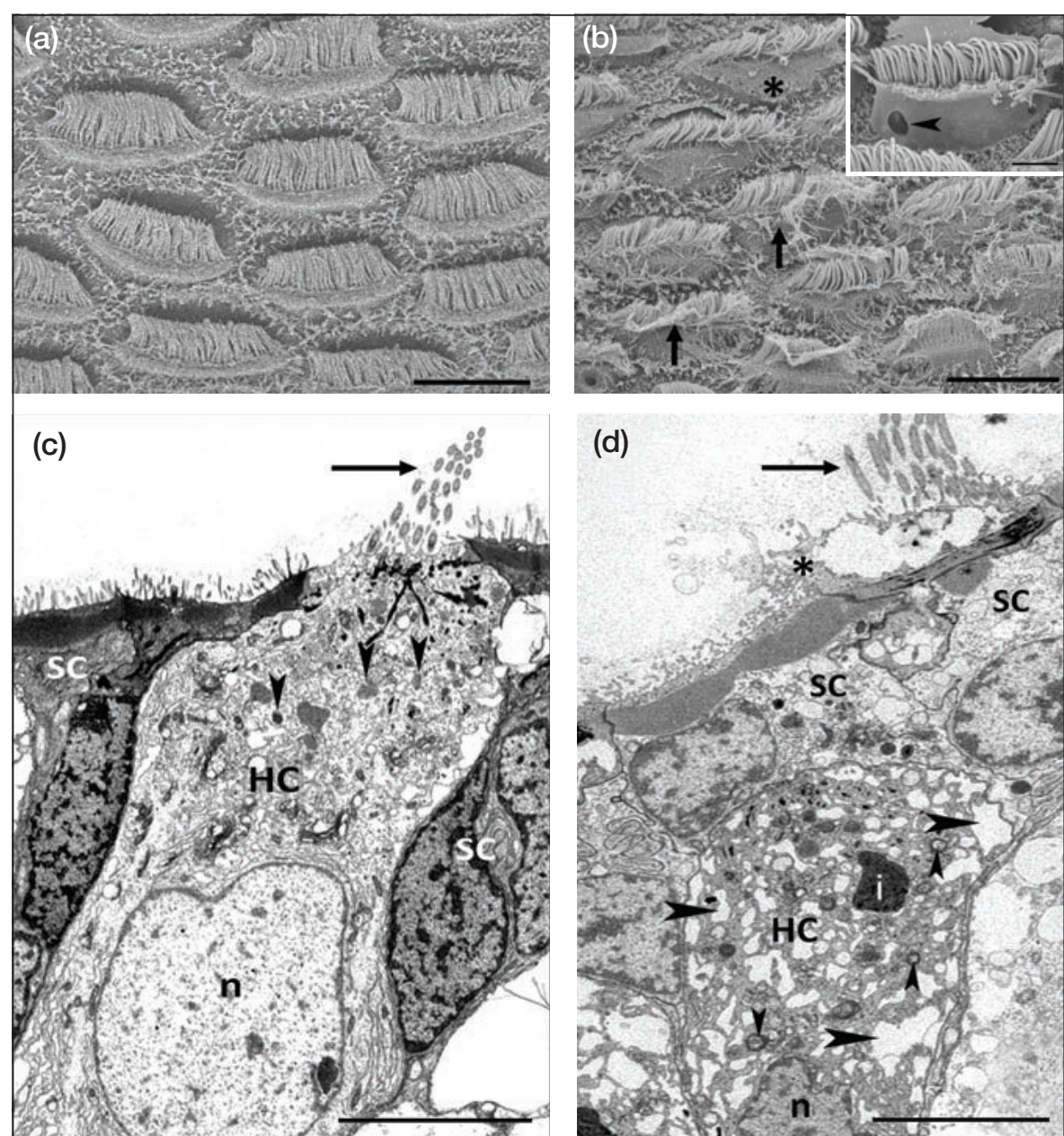

Figure 3. $(a, b)$ Scanning electron microscope and $(c, d)$ transmission electron microscope images of Sepia officinalis macula statica princeps. ( $a$ and c) Control specimens, not exposed to sound; ( $b$ and d) sound-exposed individuals. (a) Normal sensory epithelium. At the apical surface of the hair cells, all kinocilia are erect and well-organized into bundles. (b) Immediately after sound exposure, hair cells show bending and disorganized kinocilia (arrows). Note also one hair-cell apical pole protruding (asterisk). (b, inset) A partially extruded hair cell, 48 hours after exposure. Note the ruptured lateral plasma membrane (arrowhead). (c) Apex of a normal hair cell (HC) in between two supporting cells (SC). The HC shows well-formed kinocilia (arrow) and healthy cytoplasmic organelles. Arrowheads point to three mitochondria. (d) Apex of a severely damaged hair cell, 48 hours after sound exposure. The top of the hair-cell body, including kinocilia (arrow) and cytoplasmic material (asterisk), is protruding into the statocyst cavity. Note the numerous vacuoles (arrowheads), damaged mitochondria (small vertical arrowheads), and a dark inclusion (i) in the portion of hair cells that remains in the epithelium. $(n)$ indicates the cell nucleus. Scale bars: $(a, b) 10 \mu \mathrm{m}$; (inset in b) $1 \mu \mathrm{m}$; (c, d) $5 \mu \mathrm{m}$.

Hastings 2009). Instead, lesions involved fusion of the stereocilia and deformation of the hair-cell body, with cell death occuring over several days or weeks (Bohne and Rabbitt 1983). However, at the periphery of a severe acoustic trauma, less dramatic damage to hair cells also includes stereociliary disorganization and fusion, and open holes are left in the epithelium following the detachment of the cell apex. This was observed in all cephalopod specimens at 48, 72, and 96 hours after exposure.

In addition to hair-cell damage, the experimental animals showed swelling of afferent dendrites and neuronal degen- eration, confirming that the neurons were also affected by the acoustic trauma. In mammalian cochlea, swelling of afferent dendrites occurs during exposure to loud noise and is the result of an excessive release of glutamate by the inner hair cell (Coyle and Puttfarcken 1993; Mumtaz et al. 1999; Pujol and Puel 1999). Under normal conditions, glutamate acts as a neurotransmitter among the inner hair cells, but has excitotoxic (toxicity to nerve cells and processes resulting from excess exposure to a neurotransmitter) effects when secreted in large quantities. The observed impacts on the statoacoustic organs of the noise-exposed cephalopods suggests the occurrence of an excitotoxic process due to an excess of glutamate, which has also been identified as a neurotransmitter in cephalopods ( Tu and Budelmann 1994; Di Cosmo et al. 2006).

\section{Discussion}

The lesions described here are new to cephalopod pathology. Their presence in all of the noise-exposed individuals (versus their absence in controls) and their clear progression over time are consistent with the effects observed in other species that have been exposed to much higher intensities of sound. Why the relatively low levels of low-frequency sound have caused such lesions in cephalopods requires further investigation. In particular, it will be critical to determine the onset mechanism of the acoustic trauma in order to determine whether these animals are more sensitive to particle motion or acoustic pressure, or to a combination of both. Future electrophysiological experiments coupled with postmortem imaging techniques are also needed to determine the tolerance-tonoise threshold of these species. However, the presence of lesions in the statocysts clearly points to the involvement of these structures in sound reception and perception. Given that low-frequency noise levels in the ocean are increasing (eg due to shipping, offshore industry, and naval maneuvers), that the role of cephalopods in marine ecosystems is only now beginning to be understood (Boyle and Rodhouse 2005), and that reliable bioacoustic data on invertebrates are scarce, future studies will have an impor- 
tant contribution to make to the sustainable use of the marine environment. These results indicate that the deleterious effects of marine noise pollution go well beyond those observed in whales and dolphins. Some activities airgun surveys, pile driving, and sonar uses - have been shown to harm a wide variety of species. However, these findings introduce an additional question about whether other activities (eg shipping, fisheries, offshore operations) that are widely represented in the oceans and produce continuous low-frequency sounds are also affecting marine fauna. If the relatively low levels and short exposure applied in this study can induce severe acoustic trauma in cephalopods, the effects of similar noise sources on these species in natural conditions over longer time periods may be considerable. Because invertebrates are clearly sensitive to noise associated with human activities, is noise, like other forms of pollution, capable of affecting the entire web of ocean life? Long-term solutions will not be easy to find, but immediate mitigation actions already exist to control noise impacts in areas where future operations are scheduled (eg seismic surveys, construction, operation of wind turbines, naval maneuvers). Making the necessary improvements will require additional scientific knowledge and stronger political resolve. Furthermore, given the global extent of the noise proliferation problem, it must ultimately be addressed on an international scale. A complex issue such as undersea noise pollution cannot be resolved quickly. Yet now is the time when important progress might be possible, before the problem of increasing noise pollution becomes intractable and its impacts irreversible.

\section{Acknowledgements}

We thank E Escolar of the vessel Nova Miriam for assistance in collecting cephalopod specimens; JM Fortuño for assistance and advice on SEM images; $\mathrm{N}$ Cortadelles for assistance and advice on TEM images; and R Villanueva and B Geary for critical and valuable comments and suggestions. The Spanish Ministry of the Environment kindly funded this work (contract 083/SDGTB/2007).

\section{References}

André M, Morell M, Mas A, et al. 2010. Best practices in management, assessment and control of underwater noise pollution. Laboratory of Applied Bioacoustics, Technical University of Catalonia, CONAT150113NS2008029. www.lab.upc.es. Viewed 3 Mar 2011.

Bohne BA and Rabbitt KD. 1983. Holes in the reticular lamina after noise exposure: implication for continuing damage in the organ of corti. Hearing Res 11: 41-53.

Boyle P and Rodhouse P (Eds). 2005. Cephalopods: ecology and fisheries. Oxford, UK: Blackwell Science.

Budelmann BU. 1992. Hearing in non-arthropod invertebrates. In: Webster DB, Fay RA, and Popper AN (Eds). The evolutionary biology of hearing. New York, NY: Springer Verlag.

Budelmann BU. 1988. Morphological diversity of equilibrium receptor systems in aquatic invertebrates. In: Atema J, Fay RR,
Popper AN, and Travolga WN (Eds). Sensory biology of aquatic animals. New York, NY: Springer Verlag.

COP (Conference of the Parties). 2008. Report of the Conference of the Parties, Convention on Migratory Species. Rome, Italy: COP.

Coyle JT and Puttfarcken PS. 1993. Oxidative stress, glutamate, and neurodegenerative disorders. Science 262: 689-95.

Di Cosmo A, Di Cristo C, and Messenger JB. 2006. L-glutamate and its ionotropic receptors in the nervous system of cephalopods. Curr Neuropharmacol 4: 305-12.

Guerra A, González AF, and Rocha F. 2004a. A review of records of giant squid in the north-eastern Atlantic and severe injuries in Architeuthis dux stranded after acoustic exploration. ICES CM 2004/CC: 29

Guerra A, González AF, Rocha F, et al. 2004b. Calamares gigantes varados. Víctimas de exploraciones acústicas. Investigación y Ciéncia 334: 35-37.

Hanlon RH and Budelmann BU. 1987. Why cephalopods are probably not "deaf". Am Nat 129: 312-17.

Hu MY, Yan HY, Chung W, et al. 2009. Acoustically evoked potentials in two cephalopods inferred using the auditory brainstem response (ABR) approach. Comp Biochem Phys A 153: 278-84.

Kaifu K, Akamatsu T, and Segawa S. 2008. Underwater sound detection by cephalopod statocyst. Fisheries Sci 74: 781-86.

Marine Mammal Commission. 2007. Marine mammals and noise: a sound approach to research and management. A report to Congress from the Marine Mammal Commission. Bethesda, MD: Marine Mammal Commission.

McCauley RD, Duncan AJ, Penrose JD, et al. 2000. Marine seismic surveys - a study of environmental implications. APPEA J 40: 692-706.

McCauley RD, Fewtrell J, and Popper AN. 2003. High intensity anthropogenic sound damages fish ears. J Acoust Soc Am 113: 638-42.

Mooney AT, Hanlon RT, Christensen-Dalsgaard J, et al. 2010. Sound detection by the longfin squid (Loligo pealei) studied with auditory evoked potentials: sensitivity to low-frequency particle motion and not pressure. J Exp Biol: 213: 3748-59.

Mumtaz JK, Seidman MD, Quirk WS, and Shivapuja BG. 1999. Effects of kynurenic acid as a glutamate receptor antagonist in the guinea pig. Eur Arch Oto-Rhino-L 257: 177-81.

Offutt GC. 1970. Acoustic stimulus perception by American lobster Homarus americanus (Decapoda). Experientia 26: 1276-78.

OSPAR Commission. 2009. Overview of the impacts of anthropogenic underwater sound in the marine environment. London, UK: OSPAR Commission.

Packard A, Karlsen HE, and Sand O. 1990. Low frequency hearing in cephalopods. J Comp Physiol A 166: 501-05.

Popper AN and Hastings MC. 2009. The effects of anthropogenic sources of sound on fishes. J Fish Biol 75: 455-89.

Pujol R and Puel JL. 1999. Excitotoxicity, synaptic repair, and functional recovery in the mammalian cochlea: a review of recent findings. Ann NY Acad Sci 28: 249-54.

Richardson WJ, Greene Jr CR, Malme CI, and Thomson DH. 1995. Marine mammals and noise. San Diego, CA: Academic Press.

Tasker ML, Amundin M, André M, et al. 2010. Marine strategy framework directive - Task Group II: Underwater noise and other forms of energy. Luxembourg, Luxembourg: Office for Official Publications of the European Communities.

Tu IJ and Budelmann BU. 1994. The effect of L-glutamate on the efferent resting activity in cephalopod statocyst. Brain Res 642: $47-58$.

Williamson R. 1995. The statocysts of cephalopods. In: Abbott NJ, Williamson R, and Maddock L (Eds). Cephalopod neurobiology: neuroscience studies in squid, octopus and cuttlefish. Oxford, UK: Oxford University Press. 